\title{
Experimental Study of a Flexible Rotor and Its Dependency on the Rolling-Bearing Temperature
}

\author{
Jean-Jacques Sinou and Fabrice Thouverez \\ Laboratoire de Tribologie et Dynamique des Systèmes, UMR CNRS 5513, Equipe Dynamique des Systèmes et des Structures, \\ École Centrale de Lyon, 69134 Ecully Cedex, France
}

Received 8 November 2005; Accepted 29 December 2005

\begin{abstract}
An experimental study of the effects of the bearing temperature on rotor unbalance responses and on the first forward and backward critical speeds is presented. Experimental tests consisted in run-ups and run-downs are realized to a flexible rotor developed and built at the Laboratoire de Tribologie et Dynamique des Systèmes, UMR CNRS 5513, École Centrale de Lyon, France. This flexible rotor is supported by two rolling bearings on flexible supports. It will be demonstrated that rolling-element bearing temperature has no-negligible effects of the amplitude and values of the forward and backward first critical speeds of the flexible rotor. In addition to the investigation of the influences of the bearing temperature on the dynamics of the flexible rotor at the first critical speeds, a brief investigation into the complete dynamic within the speed range of interest is also conducted. The purpose of this is to examine in detail the vibrational phenomena of the flexible rotor and to detect some characteristics dynamic behaviour due to the presence of rolling-element bearings.
\end{abstract}

Copyright (c) 2006 J.-J. Sinou and F. Thouverez. This is an open access article distributed under the Creative Commons Attribution License, which permits unrestricted use, distribution, and reproduction in any medium, provided the original work is properly cited.

\section{INTRODUCTION}

Since the beginning of rotordynamic design, interest in improving engine performance, reducing operating and maintenance costs, assuring the safety of rotating machinery, has drastically increased. It was recognized that one of the most important mechanical elements to take into account was bearings due to their large influence on the dynamic behaviour of rotating machinery [1-7]. The two major types bearings that are currently used to support gas turbine engine rotors are rolling-element bearings and squeeze film dampers. Various theoretical and experimental works [1-15] performed over the last three decades have indicated the advantages of using rolling-element bearing or fluid-film bearing for various industrial applications. Both bearings have advantages and disadvantages. Therefore, they may be selected depending on the industrial applications. Fluid-film bearings are widely used in rotating machinery because they have an important damping effect on rotors and a long life limit with good lubrication $[1,2,4]$. However, these rolling components may cause self-excited vibrations which lead catastrophic failure. In contrast to fluid-film bearings, rollingelement bearings allow to rotors to be more stable. Moreover, rolling-element bearings are convenient to use. Then, for an aircraft engine, rolling-element bearings are commonly used. As explained by many authors [2-5, 7], this design is generally preferred in aircraft engine due to their durability and low-power requirements. Vance [4] added that a rollingelement bearing usually gives an early warning which may avoid unexpected accidents, thereby losing the aircraft power and compromising flight safety. In the last years, rollingelement bearings in aircraft engines are being pushed to their limits in order to improve engine performance.

One of the problems that may be encountered is the evolution of the dynamic behaviour of rotors due to the variations of the operating bearing temperatures within the speed range of interest and more particularly around the $1 \mathrm{X}$ and $2 \mathrm{X}$ resonances of rotors. Effectively, the evolutions of the operating temperature for the rolling bearings may be the result of a number of factors including, for example, the operating speed, the amount of lubricant in the rolling bearing, the shaft loading, the misalignment, the ambient temperature, and so forth.

This article concerns the effects of the rolling-element bearing temperature on the dynamic behaviour of a flexible rotor. The control parameters for experimental studies will be rolling-bearing temperature, rotational speed, and level of unbalance. At first, the flexible rotor considered for this experimental study will be briefly described. Then the dynamic behaviour of this rotor within the speed range of interest will 


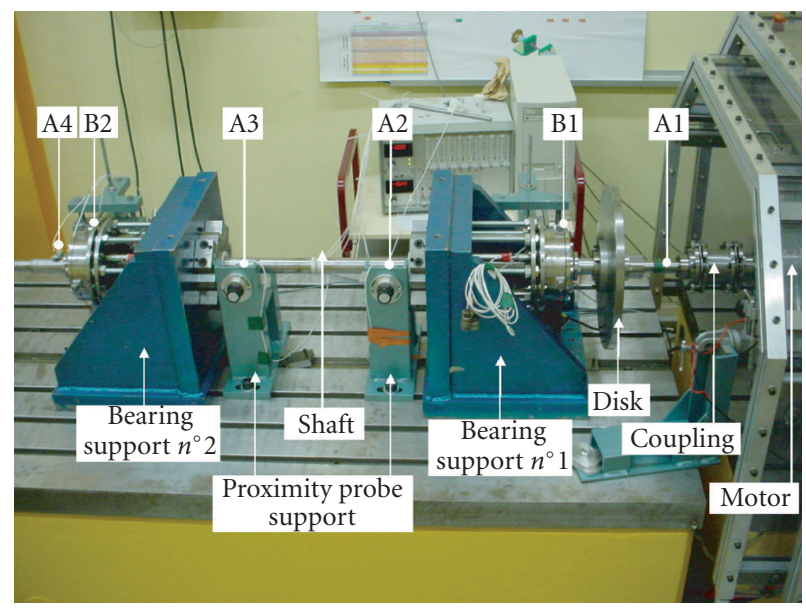

FIgURE 1: The test rig.

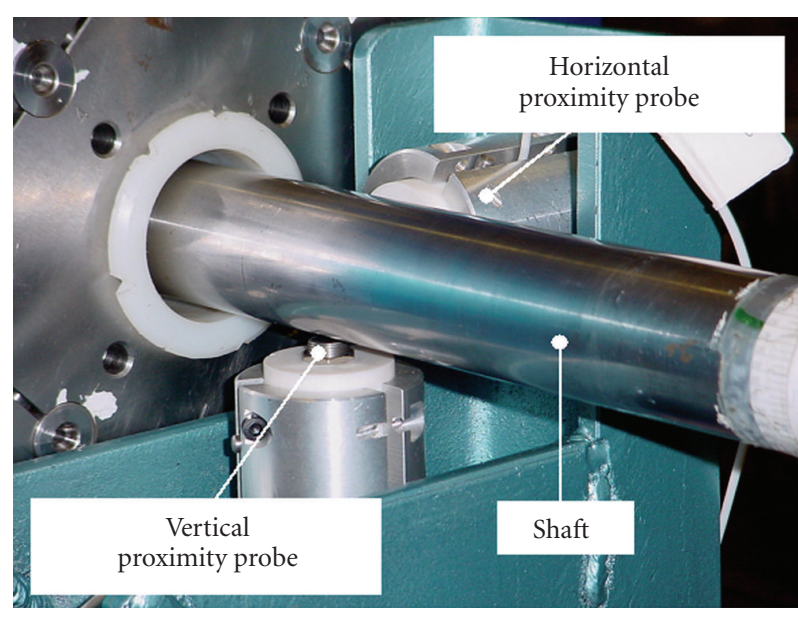

Figure 2: Proximity probes.

be investigated. Finally, experimental tests for various operational bearing temperature, various run-ups and run-downs, and various mass unbalances will be performed in order to evaluate the influence of the bearing temperature on the rotor dynamics around the $1 \mathrm{X}$ and $2 \mathrm{X}$ resonances.

\section{DESCRIPTION OF THE TEST RIG}

An overall view of the test rig is given on Figure 1. The test rig has been fully described by Sinou et al. [16] and summarized here. The rotor is composed of a horizontal shaft $(1.7 \mathrm{~m}$ long, $0.04 \mathrm{~m}$ diameter), one disk (0.02 thickness, $0.4 \mathrm{~m}$ diameter) two bearings and two bearings support. The rotor is connected to an electrical motor by a flexible coupling. The system is placed over a massive concrete table isolated from the environment by rubber slabs.

To obtain a good description of the dynamic of the rotor, the displacements and the accelerations of the structure are measured in several transversal planes. Four planes are placed to measure the transversal displacements of the shaft, by using noncontact displacement transducers (Figure 2).

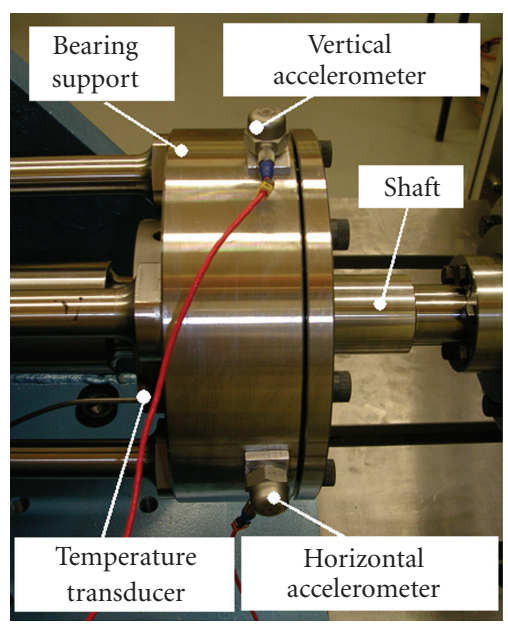

FIgURE 3: Accelerometers and temperature transducer.

Two measurement planes are placed in the bearing supports and the planes consist of accelerometers (Figure 3). All the measuring planes are illustrated in Figure 1 (planes A1, A2, $\mathrm{A} 3$, and A4 for the noncontact displacement transducers and planes B1 and B2 for the accelerometers). The test rig has also a phase meter and two temperature transducers at each bearing supports (Figure 3 ) to monitor the bearing temperatures. It is important to define where the bearing temperature is taken due to the fact that the temperature at the bearing surface will be higher than at the outside surface of the bearing cap. For the following, we define temperature as that taken at the bearing cap surface. All the transducers are connected to an HP3565A mainframe.

\section{EXPERIMENTAL RESULTS}

In this section, experimental tests will be firstly conducted in order to define the dynamical behaviour of the flexible rotor and detect some characteristics dynamic behaviour of the rotor due to the presence of rolling-element bearings. Then, experimental tests for various bearing temperatures will be 


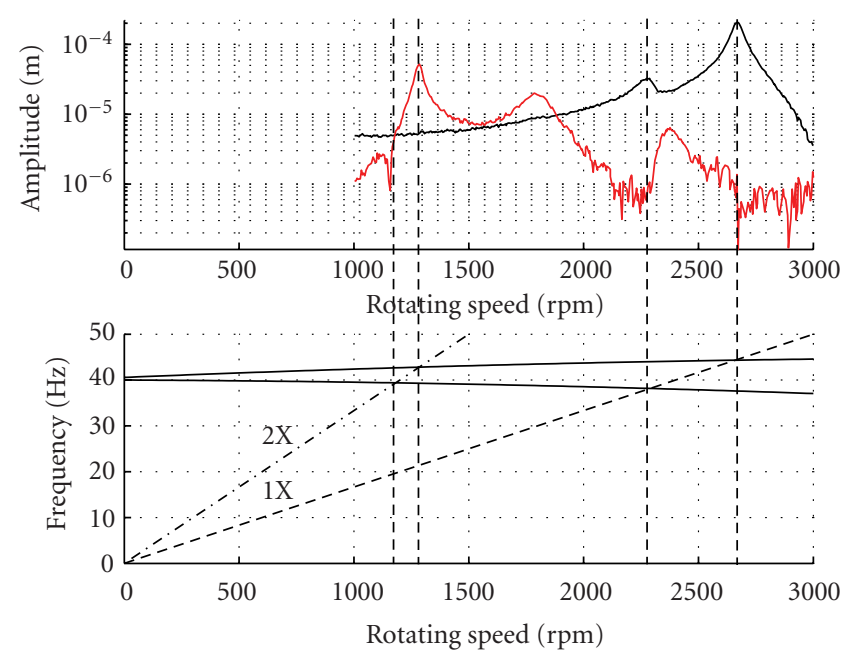

Figure 4: Unbalance response (black line $=1$ st order, red line $=2$ nd order) and Campbell diagram at the bearing support B1.

investigated in order to examine the influence of bearing temperatures on the $1 \mathrm{X}$ and $2 \mathrm{X}$ resonances of the flexible rotor.

\subsection{Dynamic behaviour of the flexible rotor}

First of all, a classical unbalance response of the rotor is undertaken. An order tracking test is performed. Figures 4 and 5 show the first and second orders of run-up test measured at the bearing support B1 and at the shaft location A3.

To better understand the different peaks observed on the unbalance response for the first and second orders, the Campbell diagram can be built by considering an experimental procedure that consists on evaluating the frequency response function of the system at several rotating speeds by using an asynchronous excitation to make the backward and forward whirl modes appear clearly. This experimental has been previously fully described by Sinou et al. [16]. The evolution of the frequency response functions of the rotor by increasing the rotating speed and the associated Campbell diagram is given in Figures 6 and 4-5, respectively. Firstly, it may be observed a separation between the first backward and forward modes at no-rotational different rotational speeds and the presence of the backward whirl at the unbalance response. These indicate some level of asymmetry for the flexible rotor due to the anisotropic nature of rolling-element bearing [15].

Moreover, an important component $2 \mathrm{X}$ in the unbalance responses of second order in the subcritical regime is observed (Figures 4 and 5). The first peak corresponds to the intersection of the $2 \mathrm{X}$ line with the curve of evolution of the forward mode, as illustrated in Figures 4 and 5. Finally, there are also two other peaks that might correspond to the second and third forward whirls of the flexible rotor. All these $2 \mathrm{X}$ peaks come probably from the combination of some level of asymmetry previously examined and the weight of the rotor [17].

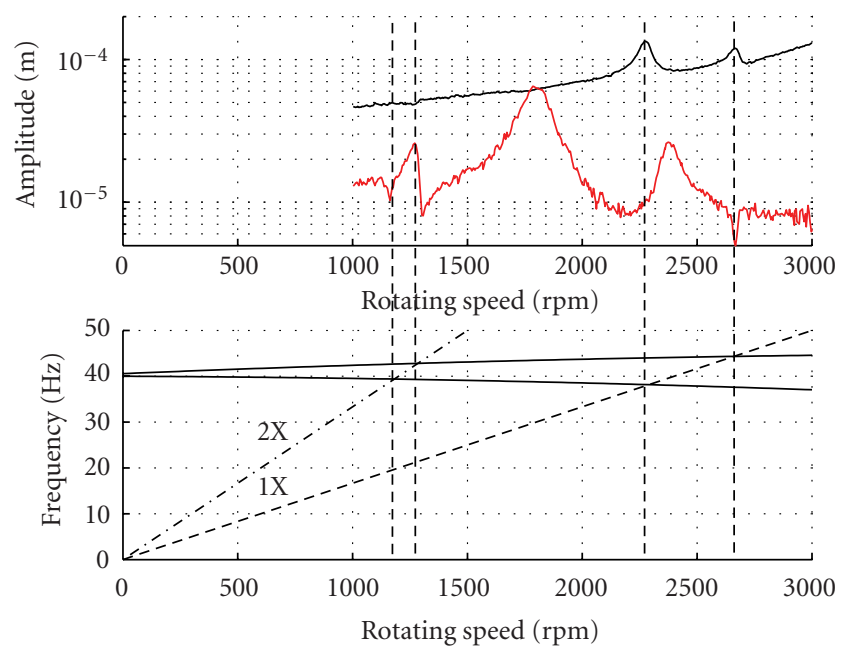

FIGURE 5: Unbalance response (black line $=1$ st order, red line $=2 \mathrm{nd}$ order) and Campbell diagram at the plane location A3.

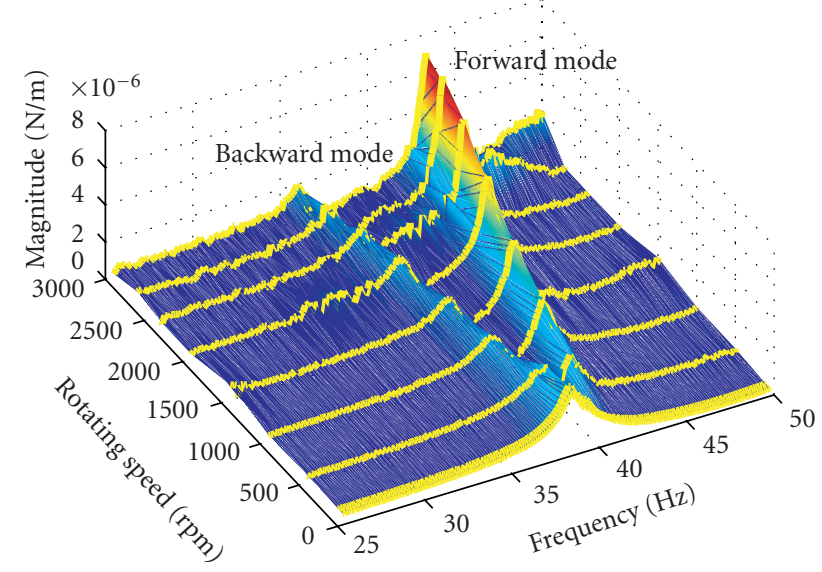

FIGURE 6: Waterfall of the Campbell diagram at the bearing support B1.

By considering a time history record type for the unbalance response of rotor, the experimental orbits of the flexible rotor at each measuring plane (four planes for the proximity probe A1, A2, A3, and A4, and the two accelerometers B1 and B2) are obtained. Then, by using an interpolation to connect each measuring planes, the operational shape of the rotor is constructed. Figures 7 and 8 illustrate the orbital evolution of the flexible rotor passing through the first backward and forward critical speed. Figure 9 indicates the orbital evolution of the flexible rotor passing through the $2 \mathrm{X}$ resonance of the first forward critical speed. The internal loop (at the end of the flexible rotor) due to the combination of the asymmetry and weight of the rotor may be clearly shown. Finally, Figure 10 shows the orbital evolution of the flexible rotor passing through the $2 \mathrm{X}$ resonance of the second forward critical speed. In this case, the internal loop (at the middle of the flexible rotor) due to the combination of the asymmetry and weight of the rotor is more difficult to be shown. 

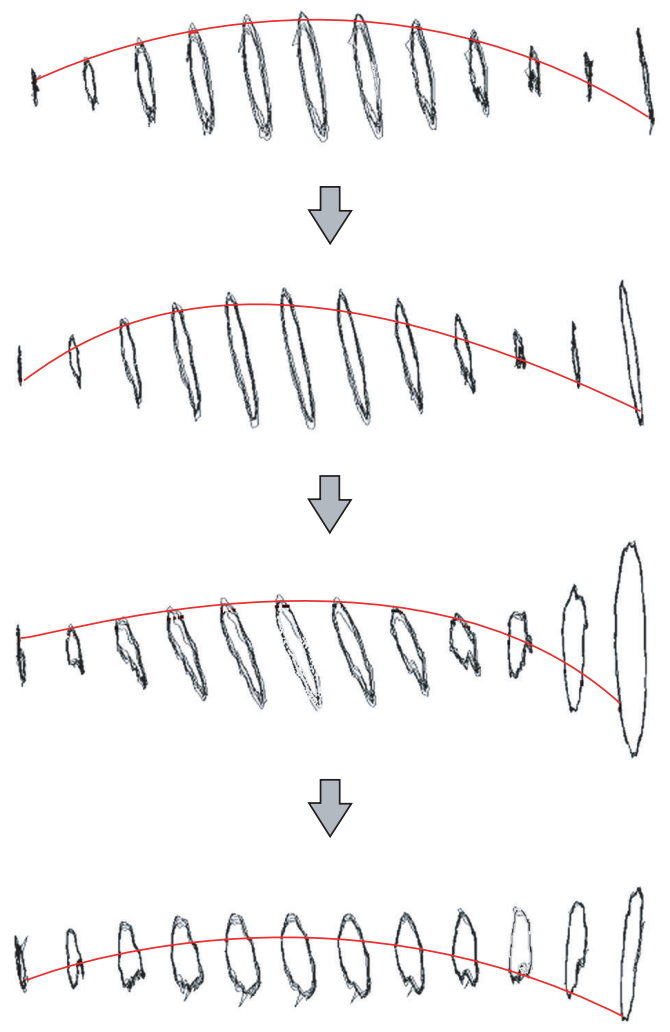

FIGURE 7: Orbital evolution of the flexible rotor passing through the first backward critical speed.

\subsection{The influences of the rolling-bearing temperatures}

In this section, run-ups (about $13 \mathrm{rpm} / \mathrm{s}$ ) and run-downs (about $17 \mathrm{rpm} / \mathrm{s}$ ) for various rolling-bearing temperature will be performed in order to estimate the effects of the rolling-bearing temperature on the rotor dynamics. First of all, run-ups and run-downs are performed with a constant bearing temperature (around $42^{\circ} \mathrm{C}$ for both run-ups and run-downs) in order to validate the repeatability of the responses of the system for the first and second orders. The results obtained are given in Figure 11. It may be clearly observed that the first and second orders for run-ups (and rundowns, respectively) are very similar (less than $0.1 \%$ for the position of the first forward and backward critical speed and the associated amplitudes, and less than $0.2 \%$ for the three peaks of the $2 \mathrm{X}$ component which correspond to the $2 \mathrm{X}$ component of the first, second, and third forward modes). So, the evolution of the first and second orders due to the variations of the rolling-bearing temperature may be clearly investigated with minor errors.

Figures 12 and 13 show the evolution of the first order at the two bearing supports (planes B1 and B2, respectively) for various rolling-bearing temperatures (increasing from $30^{\circ} \mathrm{C}$ to $42^{\circ} \mathrm{C}$ ) during run-ups. Table 1 gives the value of the first forward critical speed and the associated amplitudes at the bearing support B1. Increasing the rolling-bearing
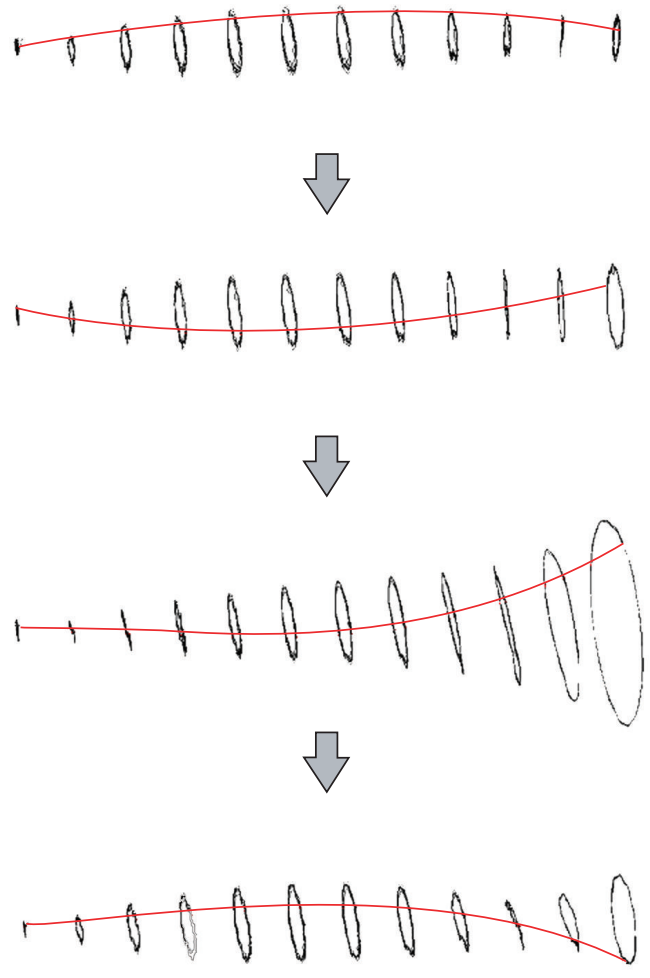

FIGURE 8: Orbital evolution of the flexible rotor passing through the first forward critical speed.

temperature decreases the position of the first forward critical speed within $1.2 \%$ at the first bearing support B1 $(1.3 \%$ at the first bearing support B2) and increases the amplitude at the first forward critical speed within $45 \%$ at the first bearing support B1 (23\% at the first bearing support B2). Concerning the first backward critical speed (around 2200$2300 \mathrm{rpm}$ ), its value decreases with increasing the rollingbearing temperature and the associated amplitude appears to be similar for all run-ups. Finally, Figure 14 illustrates the evolution of the associated second order at the bearing support B1. It may be observed that the amplitude of the three peaks (corresponding to the $2 \mathrm{X}$ component of the first, second, and third forward modes) and the associated rotating speed are very similar for all the run-ups and the various temperatures.

Figures 15, 16, and 17 illustrate the evolution of the first and second orders at the bearing supports for various rollingbearing temperatures (increasing from $30^{\circ} \mathrm{C}$ to $42^{\circ} \mathrm{C}$ ) during run-downs. The value of the first forward critical speed and the associated amplitudes at the bearing support B1 are given in Table 2. The results are in accordance with the run-ups: the first forward critical speed decreases within $1.1 \%$ at the first bearing support B1 (1.3\% at the first bearing support B2) and the amplitude at the first forward critical speed decreases within $64 \%$ at the first bearing support B1 $(23 \%$ at the first bearing support B2) when the rolling-bearing temperature 

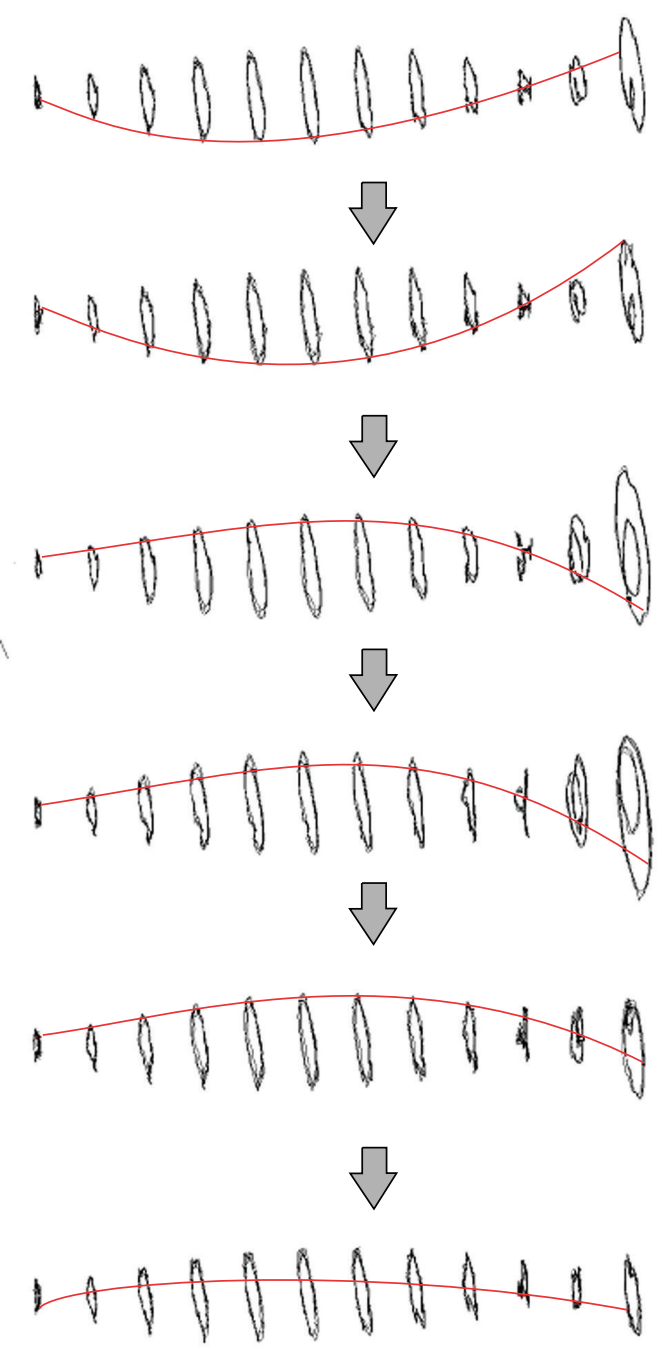

FIgURE 9: Orbital evolution of the flexible rotor passing through the $2 \mathrm{X}$ resonance of the first forward critical speed.

increases. The backward first critical speed (with the associated amplitude) and the three peaks of the $2 \mathrm{X}$ components are very similar for all the run-downs.

Considering these run-ups and run-downs, it may be concluded that the rolling-bearing temperature influences the value of the critical speed and is one of the factors contributing to the unbalance of the flexible rotor.

Now, we perform another series of tests in which the flexible rotor is previously balanced in order to minimize unbalance. These following tests are realized in order to better understand the influence of the rolling-bearing temperature on the dynamic behaviour of the flexible rotor. Figures 18 and 19 illustrate the evolution of the first order at the bearing locations $\mathrm{B} 1$ and $\mathrm{B} 2$ for various rolling-bearing temperatures (increasing from $20^{\circ} \mathrm{C}$ to $45^{\circ} \mathrm{C}$ ). As observed for the previous experimental tests, increasing the bearing temperatures decreases the first backward and forward critical speeds within $1-2 \%$. Moreover, the variation in amplitudes versus the bearing temperature at the first forward critical speed appears to
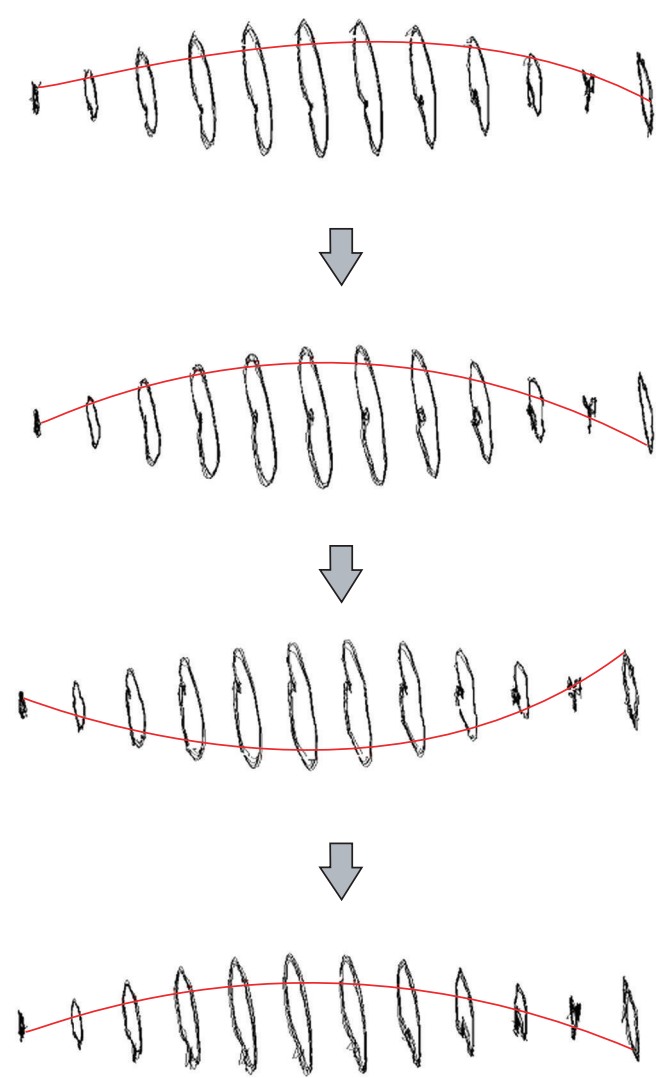

FIGURE 10: Orbital evolution of the flexible rotor passing through the $2 \mathrm{X}$ resonance of the second forward critical speed.

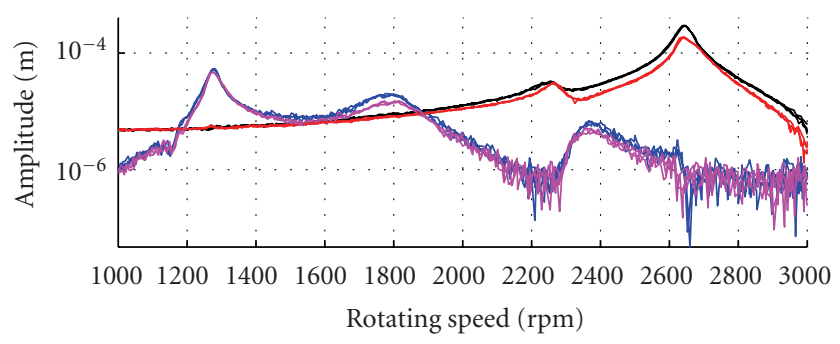

(a)

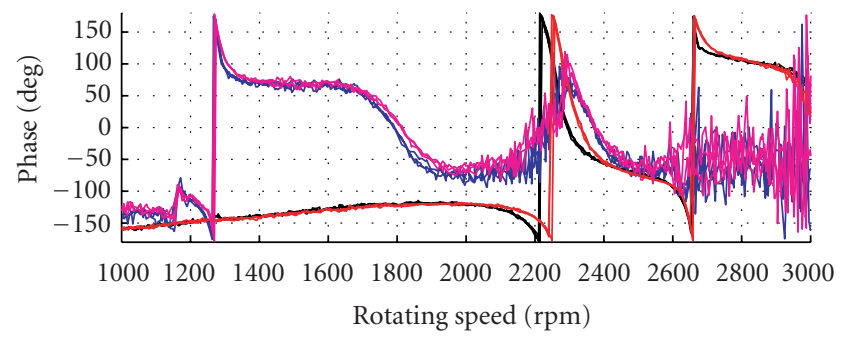

(b)

FIGURE 11: Unbalance responses at the bearing support B1 for runup and run-down (black line $=1$ st-order run-ups; red line $=1$ storder run-downs; blue line $=2$ nd-order run-ups; magenta line $=$ 2nd-order run-downs). 


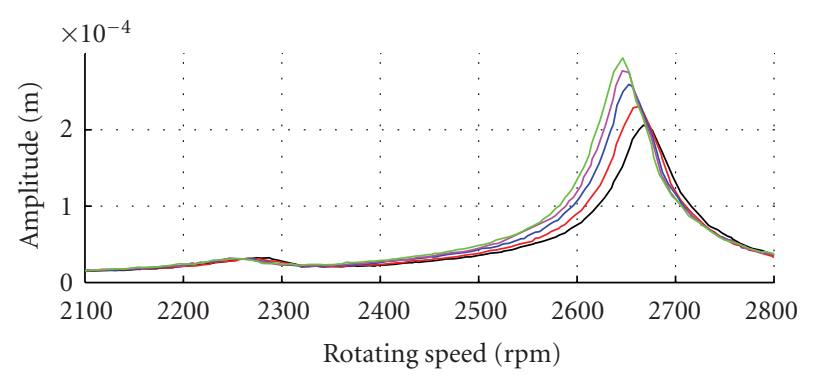

(a)

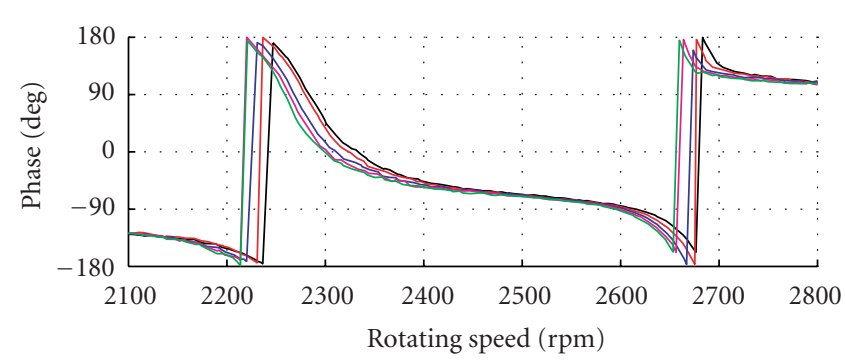

(b)

Figure 12: Unbalance responses of the 1st order during run-up for various bearing temperatures at the support $\mathrm{B} 1$ (black line $=30^{\circ} \mathrm{C}$; red line $=35^{\circ} \mathrm{C}$; blue line $=38^{\circ} \mathrm{C}$; magenta line $=40^{\circ} \mathrm{C}$; green line $=$ $\left.42^{\circ} \mathrm{C}\right)$.

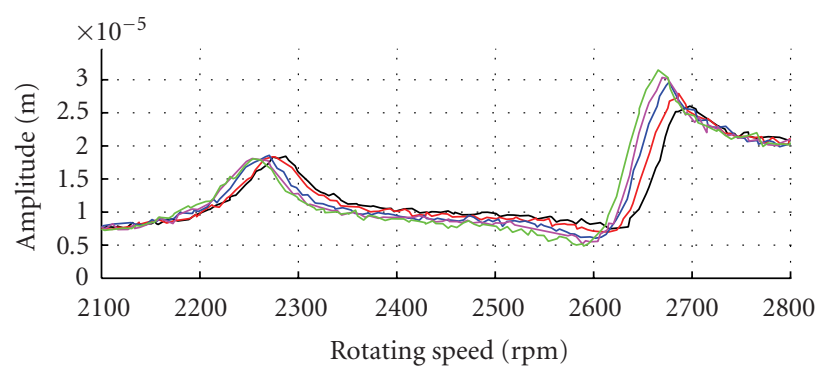

(a)

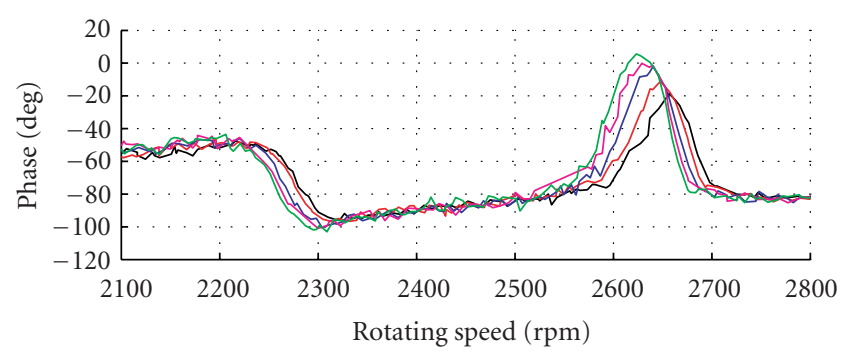

(b)

FIGURE 13: Unbalance responses of the 1st order during run-up for various bearing temperatures at the location plane A3 (black line = $30^{\circ} \mathrm{C}$; red line $=35^{\circ} \mathrm{C}$; blue line $=38^{\circ} \mathrm{C}$; magenta line $=40^{\circ} \mathrm{C}$; green line $\left.=42^{\circ} \mathrm{C}\right)$.
TABLE 1: Amplitudes and critical speeds at the bearing support B1 for run-ups.

\begin{tabular}{l|cc}
\hline \multirow{2}{*}{ Bearing temperature } & \multicolumn{2}{|c}{ Order 1 } \\
& Amplitude & Rational speed \\
\hline $30-32^{\circ} \mathrm{C}$ & $190 \mu \mathrm{m}$ & $2672 \mathrm{rpm}$ \\
$33-35^{\circ} \mathrm{C}$ & $220 \mu \mathrm{m}$ & $2662 \mathrm{rpm}$ \\
$38-38^{\circ} \mathrm{C}$ & $240 \mu \mathrm{m}$ & $2653 \mathrm{rpm}$ \\
$40-40^{\circ} \mathrm{C}$ & $260 \mu \mathrm{m}$ & $2650 \mathrm{rpm}$ \\
$42-41^{\circ} \mathrm{C}$ & $275 \mu \mathrm{m}$ & $2647 \mathrm{rpm}$ \\
\hline
\end{tabular}

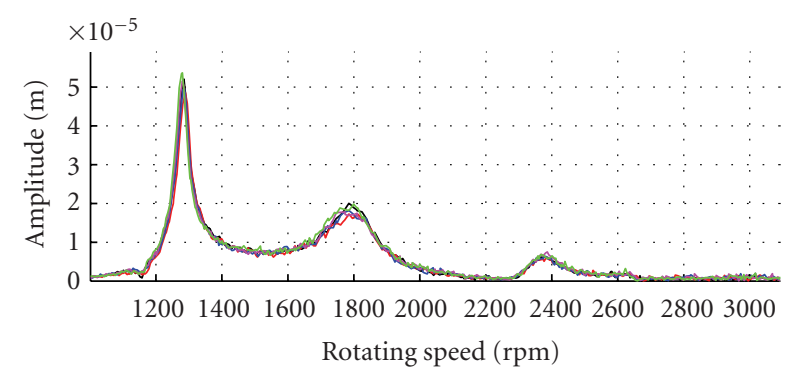

(a)

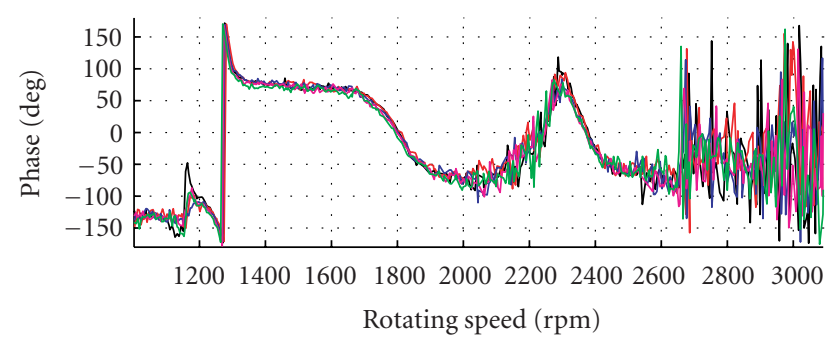

(b)

FIGURE 14: Unbalance responses of the 2nd order during run-up for various bearing temperatures at the bearing support B1 (black line $=30^{\circ} \mathrm{C}$; red line $=35^{\circ} \mathrm{C}$; blue line $=38^{\circ} \mathrm{C}$; magenta line $=40^{\circ} \mathrm{C}$; green line $=42^{\circ} \mathrm{C}$ ).

be very important too. However, in this case, the amplitude of the first forward critical speed increases when the bearing temperature increases.

Considering all the experimental tests, it may be concluded that the evolution of the forward and backward critical speeds decrease when the rolling-bearing increases. However, the evolution of the amplitudes at the critical speeds is more complex due to the contribution of the rolling-bearing temperature on the unbalance of the flexible rotor. Then, a flexible rolling bearing rotor must be balanced in the service conditions including the operating temperature.

\section{CONCLUSIONS}

This paper presents the dynamical behaviour of a flexible rotor supported by two rolling-element bearing supports. Considering the unbalance responses and the Campbell diagram, the existence of the component $2 \mathrm{X}$ in the responses of the 


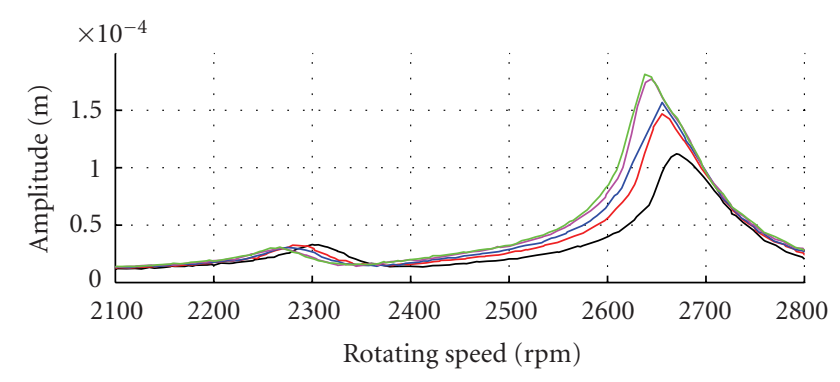

(a)

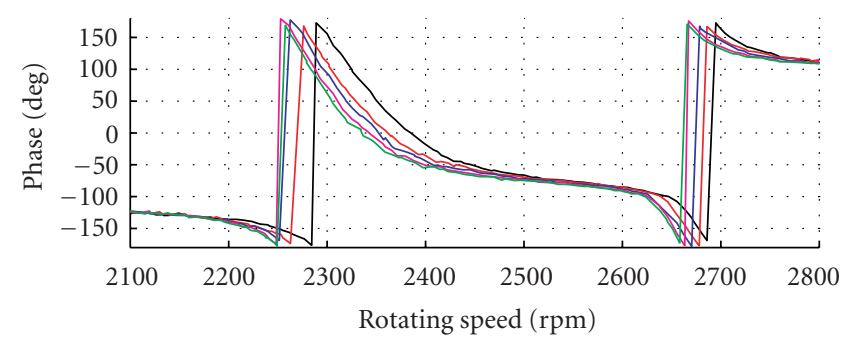

(b)

FIGURE 15: Unbalance responses of the 1st order during run-down for various bearing temperatures at the bearing support B1 (black line $=33^{\circ} \mathrm{C}$; red line $=36^{\circ} \mathrm{C}$; blue line $=40^{\circ} \mathrm{C}$; magenta line $=42^{\circ} \mathrm{C}$; green line $\left.=44^{\circ} \mathrm{C}\right)$.

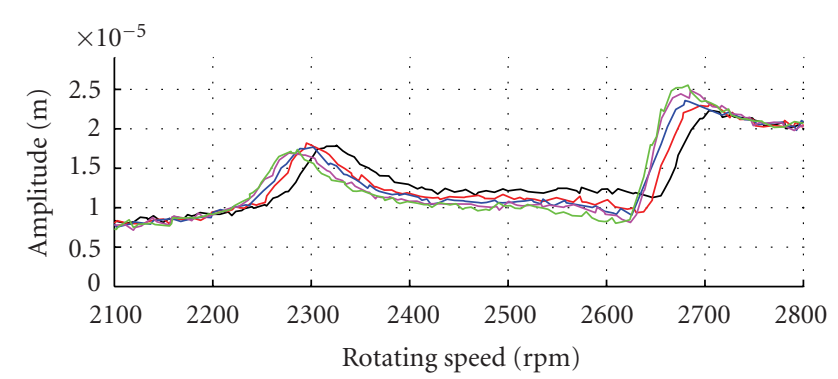

(a)

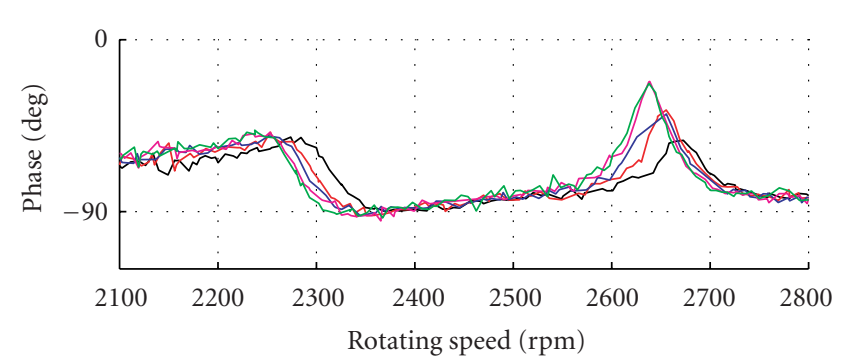

(b)

FIGURE 16: Unbalance responses of the 1st order during run-down for various bearing temperatures at the plane location A3 (black line $=33^{\circ} \mathrm{C}$; red line $=36^{\circ} \mathrm{C}$; blue line $=40^{\circ} \mathrm{C}$; magenta line $=42^{\circ} \mathrm{C}$; green line $=44^{\circ} \mathrm{C}$ ).

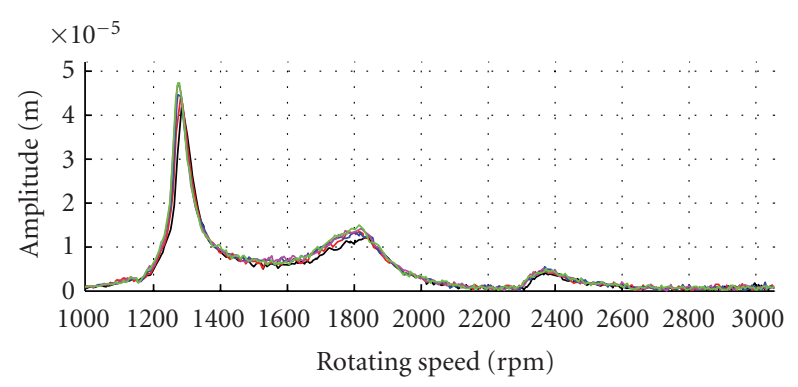

(a)

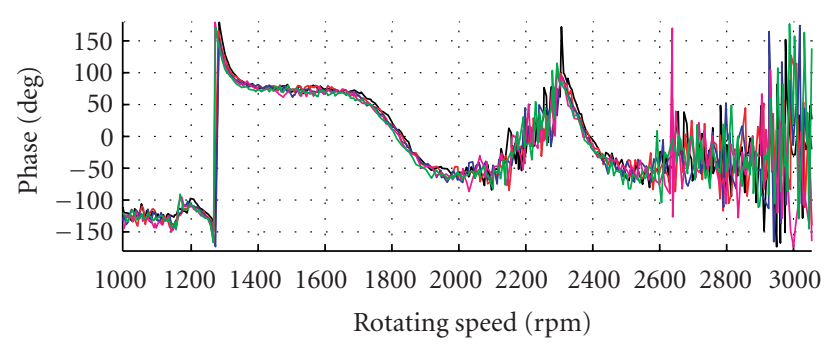

(b)

FIGURE 17: Unbalance responses of the 2nd order during run-down for various bearing temperatures at the bearing support B1 (black line $=33^{\circ} \mathrm{C}$; red line $=36^{\circ} \mathrm{C}$; blue line $=40^{\circ} \mathrm{C}$; magenta line $=42^{\circ} \mathrm{C}$; green line $=44^{\circ} \mathrm{C}$ ).

TABLe 2: Amplitudes and critical speeds at the bearing support B1 for run-downs.

\begin{tabular}{l|cc}
\hline \multirow{2}{*}{ Bearing temperature } & \multicolumn{2}{c}{ Order 1 } \\
& Amplitude & Rational speed \\
\hline $34-36^{\circ} \mathrm{C}$ & $105 \mu \mathrm{m}$ & $2670 \mathrm{rpm}$ \\
$36-39^{\circ} \mathrm{C}$ & $140 \mu \mathrm{m}$ & $2660 \mathrm{rpm}$ \\
$40-42^{\circ} \mathrm{C}$ & $150 \mu \mathrm{m}$ & $2655 \mathrm{rpm}$ \\
$41-43^{\circ} \mathrm{C}$ & $165 \mu \mathrm{m}$ & $2645 \mathrm{rpm}$ \\
$42-44^{\circ} \mathrm{C}$ & $170 \mu \mathrm{m}$ & $2640 \mathrm{rpm}$ \\
\hline
\end{tabular}

flexible rotor was investigated. The combination of the asymmetry of the rolling-element bearing and the weight of the rotor appears to be the reason of the $2 \mathrm{X}$ resonance at half of the first and second forward critical speeds.

We have compared the rolling-bearing rotor behaviour in the operational temperature range. The experimental tests suggest that the first forward and backward critical speeds increase slightly as the temperature decreases. This suggests that many aspects and studies (i.e., calculating the critical speeds, stability analysis, etc.) of a rolling-bearing flexible rotor can be developed with minor error by neglecting the influence of temperature. However, the consideration of the effects of the rolling-bearing temperature may be helpful in order to better understand the level amplitude at the critical 


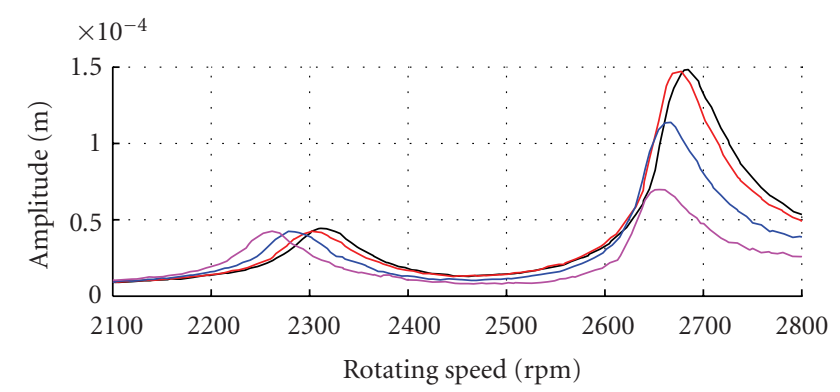

(a)

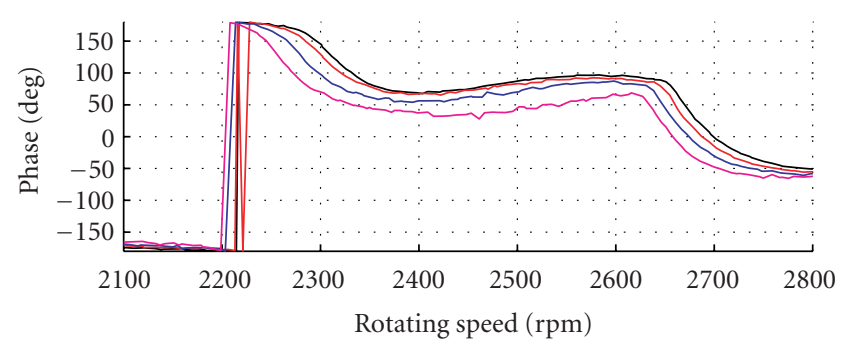

(b)

FIGURE 18: Unbalance responses of the 1st order for various bearing temperatures at the bearing support $\mathrm{B} 1$ (black line $=25^{\circ} \mathrm{C}$; red line $=35^{\circ} \mathrm{C}$; blue line $=40^{\circ} \mathrm{C}$; magenta line $=48^{\circ} \mathrm{C}$ ).

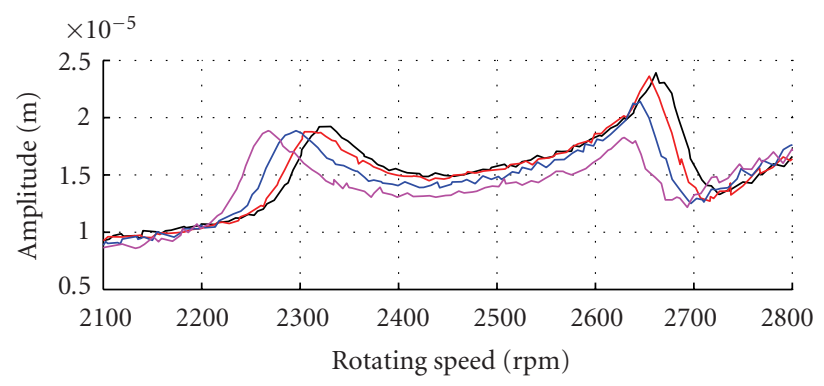

(a)

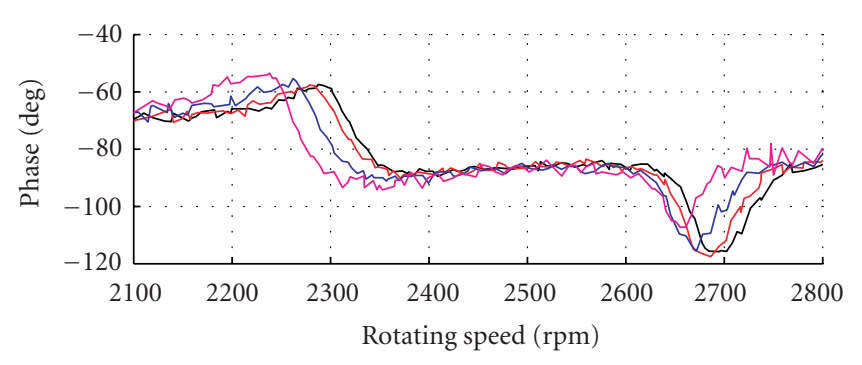

(b)

FIGURE 19: Unbalance responses of the 1st order for various bearing temperatures at the plane location $\mathrm{A} 3$ (black line $=25^{\circ} \mathrm{C}$; red line $=$ $35^{\circ} \mathrm{C}$; blue line $=40^{\circ} \mathrm{C}$; magenta line $=48^{\circ} \mathrm{C}$ ). speeds of the rotor and to be able to undertake complex analysis where all the parameters that influence the dynamic of the rotor need to be considered.

\section{REFERENCES}

[1] D. E. Bently, C. T. Hatch, and B. Grissom, Fundamentals of Rotating Machinery Diagnostics, Bently Pressurized Bearing Press, Minden, Nev, USA, 2002.

[2] F. F. Ehrich, Handbook of Rotordynamics, McGraw-Hill, New York, NY, USA, 1992.

[3] T. A. Harris, Rolling Bearing Analysis, John Wiley \& Sons, New York, NY, USA, 2001.

[4] J. M. Vance, Rotordynamics of Turbomachinery, John Wiley \& Sons, New York, NY, USA, 1988.

[5] T. Yamamoto and Y. Ishida, Linear and Nonlinear Rotordynamics: A Modern Treatment with Applications, John Wiley \& Sons, New York, NY, USA, 2001.

[6] M. Lalanne and G. Ferraris, Rotordynamics Prediction in Engineering, John Wiley \& Sons, New York, NY, USA, 1990.

[7] D. Childs, Turbomachinery Rotordynamics: Phenomena, Modeling, and Analysis, John Wiley \& Sons, New York, NY, USA, 1993.

[8] R. Tiwari, A. W. Lees, and M. I. Friswell, "Identification of dynamic bearing parameters: a review," The Shock and Vibration Digest, vol. 36, no. 2, pp. 99-124, 2004.

[9] E. J. Hahn and P. Y. Chen, "Harmonic balance analysis of general squeeze film damped multidegree-of-freedom rotor bearing systems," Journal of Tribology, vol. 116, no. 1, pp. 499-507, 1994.

[10] S. P. Harsha, K. Sandeep, and R. Prakash, "Non-linear dynamic behaviors of rolling element bearings due to surface waviness," Journal of Sound and Vibration, vol. 272, no. 3-5, pp. 557-580, 2004.

[11] E. Hashish and T. C. Sankar, "Finite element and modal analyses of rotor-bearing systems under stochastic loading conditions," ASME Journal of Vibration, Acoustics, Stress, and Reliability in Design, vol. 106, no. 1, pp. 80-89, 1984.

[12] J. T. Sopanen and A. M. Mikkola, "Ball bearing vibration analysis including localized and distributed defects," in Proceedings of ASME Design Engineering Technical Conferences and Computers and Information in Engineering Conference, Chicago, Ill, USA, September 2003.

[13] M. Tiwari, K. Gupta, and O. Prakash, "Dynamic response of an unbalanced rotor supported on ball bearings," Journal of Sound and Vibration, vol. 238, no. 5, pp. 757-779, 2000.

[14] M. Tiwari, K. Gupta, and O. Prakash, "Effect of radial internal clearance of a ball bearing on the dynamics of a balanced horizontal rotor," Journal of Sound and Vibration, vol. 238, no. 5, pp. 723-756, 2000.

[15] M. Tiwari, K. Gupta, and O. Prakash, "Experimental study of a rotor supported by deep groove ball bearing," International Journal of Rotating Machinery, vol. 8, no. 4, pp. 243-258, 2002.

[16] J.-J. Sinou, C. Villa, and F. Thouverez, "Experimental and numerical investigations of a flexible rotor on flexible bearing supports," International Journal of Rotating Machinery, vol. 2005, no. 3, pp. 179-189, 2005.

[17] A. Dimarogonas, Vibration for Engineers, Prentice-Hall, Upper Saddle River, NJ, USA, 1996. 

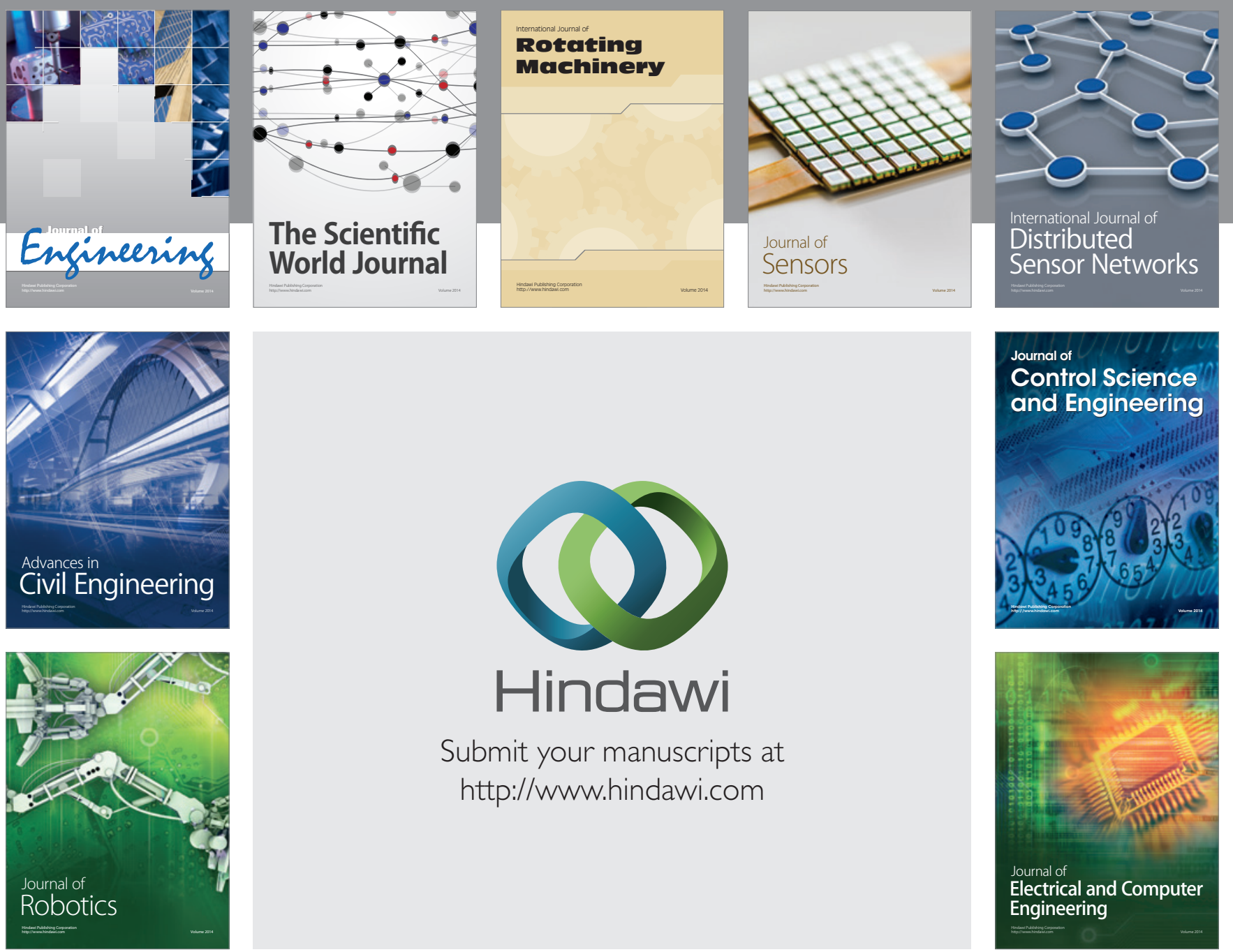

Submit your manuscripts at

http://www.hindawi.com
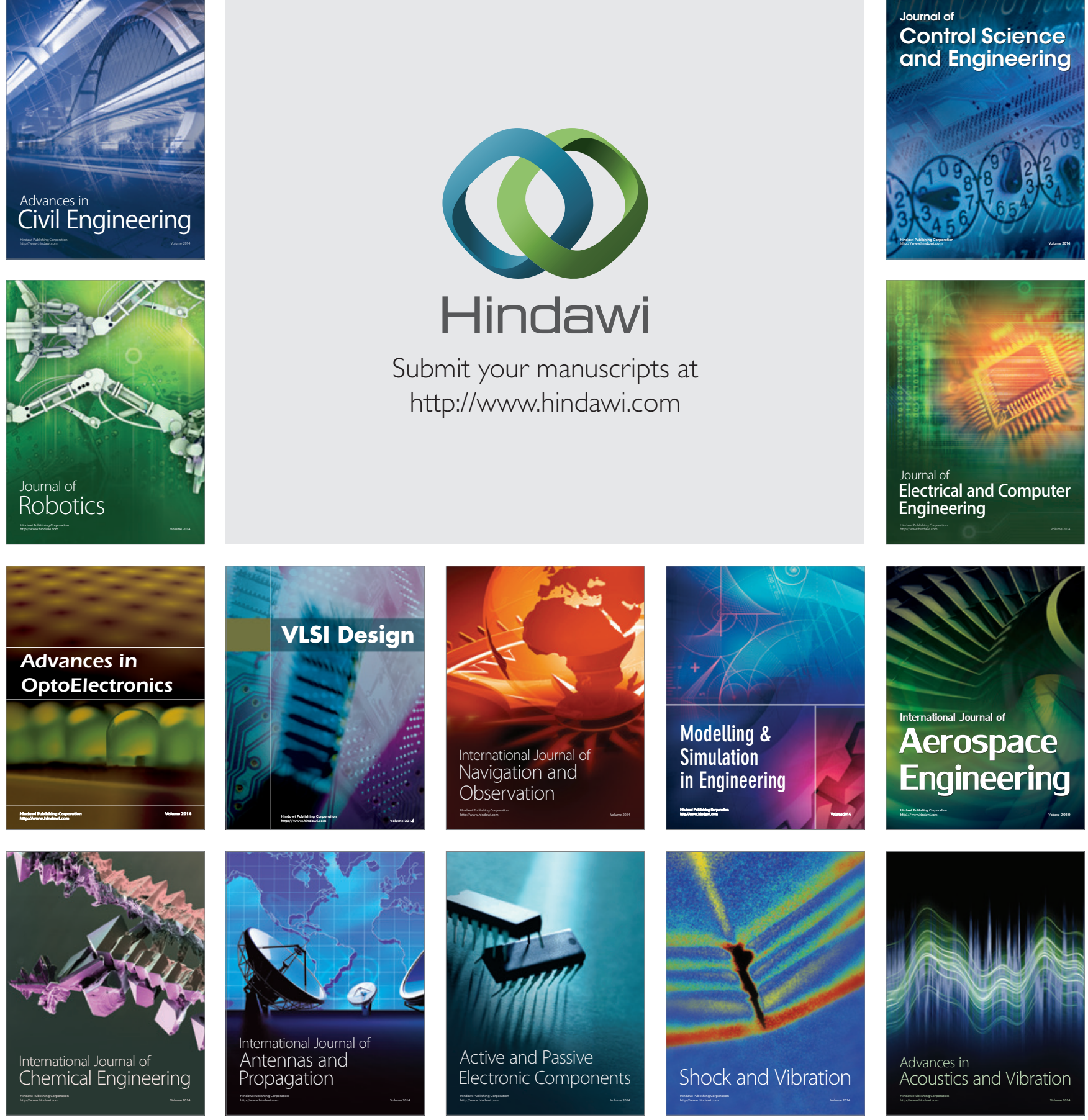